\title{
LIMITED BRAIN DIFFUSION OF THE GLUCOCORTICOID RECEPTOR AGONIST RU28362 FOLLOWING I.C.V. ADMINISTRATION: IMPLICATIONS FOR I.C.V. DRUG DELIVERY AND GLUCOCORTICOID NEGATIVE FEEDBACK IN THE HYPOTHALAMIC-PITUITARY-ADRENAL AXIS
}

\author{
A. B. FRANCIS, ${ }^{*}$ T. W. W. PACE, A. B. GINSBERG, \\ B. A. RUBIN AND R. L. SPENCER \\ Campus Box 345, University of Colorado at Boulder, Boulder, CO \\ 80309, USA
}

\begin{abstract}
The experiments described herein present a method for tracking diffusion of the glucocorticoid receptor agonist RU28362 in brain following i.c.v. drug administration. A useful property of glucocorticoid receptor is that it is primarily cytoplasmic when unbound and rapidly translocates to the nucleus when bound by ligand. Thus, removal of endogenous glucocorticoids by adrenalectomy allows us to identify brain regions with activated glucocorticoid receptor after i.c.v. glucocorticoid receptor agonist treatment by examining the presence or absence of nuclear glucocorticoid receptor immunostaining. We have previously demonstrated that an i.p. injection of $150 \mu \mathrm{g} / \mathrm{kg}$ RU28362 $1 \mathrm{~h}$ prior to restraint stress is sufficient to suppress stress-induced hypothalamic-pituitary-adrenal axis hormone secretion [Ginsberg AB, Campeau S, Day HE, Spencer RL (2003) Acute glucocorticoid pretreatment suppresses stress-induced hypothalamic-pituitary-adrenal axis hormone secretion and expression of corticotropin-releasing hormone hnRNA but does not affect c-fos mRNA or fos protein expression in the paraventricular nucleus of the hypothalamus. J Neuroendocrinol 15:1075-1083]. We report here, however, that in rats i.c.v. treatment with a high-dose of RU28362 $(1 \mu \mathrm{g})$ $1 \mathrm{~h}$ prior to stressor onset does not suppress stress-induced hypothalamic-pituitary-adrenal axis activity. We then performed a series of experiments to examine the possible differences in glucocorticoid receptor activation patterns in brain and pituitary after i.c.v. or i.p. treatment with RU28362. In a dose-response study we found that $1 \mathrm{~h}$ after i.c.v. injection of RU28362 $(0.001,0.1$ and $1.0 \mu \mathrm{g})$ glucocorticoid receptor nuclear immunoreactivity was only evident in brain tissue immediately adjacent to the lateral or third ventricle, including the medial but not more lateral portion of the medial parvocellular paraventricular nucleus of the hypothalamus. In contrast, i.p. injection of RU28362 produced a uniform predominantly nuclear glucocorticoid receptor immunostaining pattern throughout all brain tissue. I.c.v. injection of the endogenous glucocorticoid receptor agonist, corticosterone $(1 \mu \mathrm{g})$ also had limited diffusion into brain tissue. Timecourse studies indicated that there was not a greater extent
\end{abstract}

${ }^{*}$ Corresponding author. Tel: +1-303-492-0777; fax: +1-303-492-2967. E-mail address: adam.francis@colorado.edu (A. B. Francis).

Abbreviations: ACTH, adrenocorticotropin hormone; ADX, adrenalectomy/adrenalectomizing; ANOVA, analysis of variance; CORT, corticosterone; CSF, cerebrospinal fluid; GR, glucocorticoid receptor; HBC, 2-hydroxypropyl-beta-cyclodextrin; HPA, hypothalamic-pituitary-adrenal; MDR, multiple drug resistance; PVN, paraventricular nucleus of the hypothalamus. of nuclear glucocorticoid receptor immunostaining present in brain after shorter (10 or $30 \mathrm{~min})$ or longer $(2$ or $3 \mathrm{~h}$ ) intervals of time after i.c.v. RU28362 injection. Importantly, time-course studies found that i.c.v. RU28362 produced significant increases in nuclear glucocorticoid receptor immunostaining in the anterior pituitary that were evident within 10 min after injection and maximal after $1 \mathrm{~h}$. These studies support an extensive literature indicating that drugs have very limited ability to diffuse out of the ventricles into brain tissue after i.c.v. injection, while at the same time reaching peripheral tissue sites. In addition, these studies indicate that significant occupancy of some glucocorticoid receptor within the paraventricular nucleus of the hypothalamus and pituitary is not necessarily sufficient to suppress stress-induced hypothalamic-pituitary-adrenal axis activity. (c) 2006 IBRO. Published by Elsevier Ltd. All rights reserved.

Key words: HPA axis, glucocorticoid receptor, i.c.v. drug delivery, drug diffusion, corticosterone, negative feedback.

I.c.v. drug delivery is widely utilized to differentiate central versus peripheral drug effects. Briefly, i.c.v. delivery is accomplished by surgically implanting a cannula into the ventricular space such that injections can be made directly into the cerebrospinal fluid. It is assumed that diffusion throughout the cerebrospinal fluid (CSF) and surrounding tissue permits delivery to areas adjacent to the site of injection as well as to more distal brain regions; however, several researchers have reported rapid clearance from the ventricular system and hence very limited diffusion into brain (Aird, 1984; Crawley et al., 1991; de Lange et al., 1994; Ghersi-Egea et al., 1996).

A central focus of the research in our laboratory is stress neurobiology and regulation of hypothalamic-pituitary-adrenal (HPA) axis activity. A hallmark of HPA axis regulation is negative feedback inhibition of corticotropin releasing hormone and adrenocorticotropin hormone $(\mathrm{ACTH})$ production and secretion by corticosterone (CORT) [for review of HPA physiology see (Dallman et al., 1987; Herman and Cullinan, 1997; de Kloet et al., 1998)].

In examining mechanisms of CORT negative feedback of the HPA axis, we performed experiments utilizing the glucocorticoid receptor (GR) agonist RU28362. Although a potent suppressor of stress-induced HPA activation when administered i.p. (Ginsberg et al., 2003), we were unable to observe an effect of RU28362 when acutely delivered i.c.v. One possible explanation for the observed lack of HPA suppression is poor drug delivery to essential sites for negative feedback. 
Taking advantage of the dynamics of GR action, we were able to assess the extent to which RU28362 could diffuse away from the ventricular system following i.c.v. injection. When unbound by ligand, GR is found exclusively in the cytoplasm; when bound, GR translocates to the nuclear compartment within minutes (Raaka and Samuels, 1983; Munck and Holbrook, 1984; Madan and DeFranco, 1993; Sackey et al., 1996). By first adrenalectomizing (ADX) animals to remove endogenous glucocorticoids, we could then employ GR immunohistochemistry to clearly identify the extent of RU28362 diffusion away from the ventricular system. Nuclear GR immunostaining indicates areas of good drug penetration, whereas cytoplasmic immunostaining indicates areas of little or no RU28362 diffusion. Because of their relative GR enrichment and putative roles in HPA control, we chose for these studies the paraventricular nucleus of the hypothalamus (PVN) and dorsal hippocampus as two brain areas in which to quantify the degree of GR activation (McEwen, 1982; Dallman et al., 1992, 1987; Herman et al., 1989, 1992).

We propose that this methodology for tracking drug distribution has several advantages over other techniques such as microdialysis or administration of radiolabeled ligand (Aird, 1984; Crawley et al., 1991; de Lange et al., 1994; Ghersi-Egea et al., 1996). Utilizing GR immunohistochemistry permits excellent anatomical resolution and identifies ligand-activated receptors rather than the mere presence of the ligand. Thus, confounds such as the presence of ligand in adjacent capillaries or low non-functional ligand levels in extracellular space are eliminated.

We present here a series of studies examining the ability of RU28362 to occupy GR in the brain and pituitary following i.c.v. injection. The results indicate that RU28362 diffusion into brain following i.c.v. injection is very limited. We saw a similar limited diffusion of CORT after i.c.v. injection. Further, we saw evidence for the presence of RU28362 in the pituitary within 10 minutes after i.c.v. administration. Thus, it appears that poor diffusion into brain and rapid clearance of drug from the CSF may permit peripheral actions of RU28362 administered i.c.v., but likely preclude direct delivery to most brain targets.

\section{EXPERIMENTAL PROCEDURES}

\section{Subjects}

Male Sprague-Dawley Rats (Harlan Laboratories, Indianapolis, IN, USA) weighing between 225 and $290 \mathrm{~g}$ were used for all experiments. Rats were allowed at least 1 week acclimation before any surgical procedures. Throughout the studies, animals were housed two per polycarbonate tub with wood shavings and were given food (Purina Rat Chow; Ralston Purina, St. Louis, MO, USA) and tap water ad libitum. The colony room lights were regulated on a 12-h light/dark cycle, with lights on at 07:00 h. Procedures for ethical treatment of animals conformed to the guidelines found in the U.S. National Institutes of Health Guide for the Care and Use of Laboratory Animals (NIH Publication No. 80-23, revised 1996) and were approved by the University of Colorado Institutional Animal Care and Use Committee. All efforts were made to minimize the number of animals used and their suffering.

\section{Experiment 1: dose response for RU28362 i.c.v.}

Animals were implanted with guide cannula in the right lateral ventricle and allowed a minimum of $7 \mathrm{~d}$ recovery. The lateral ventricle injection site was chosen for both its proximity to forebrain areas as well as its position "upstream" from other CSF reservoirs. On the test day, animals received vehicle $(n=6)$ [40\% 2-hydroxypropyl-betacyclodextrin (HBC, H107; Research Biochemicals International, Natick, MA, USA) in saline], $0.005 \mu \mathrm{g}$ RU28362 $(n=7)$ (a gift from the former pharmaceutical company Roussel Uclaf, France), $0.1 \mu \mathrm{g}$ RU28362 $(n=7)$, or $1.0 \mu \mathrm{g} \mathrm{RU28362}(n=6)$ in a total volume of $2 \mu \mathrm{l}$. Following injection, rats were returned to their home cages. After $1 \mathrm{~h}$, subjects were placed in plastic restrainers [clear, ventilated, cylindrical Plexiglas tubes with adjustable length $(15.5 \pm 2.5 \mathrm{~cm}$ length)] for 60 minutes. Blood samples were collected via tail nick at the beginning of restraint, 30 and 60 minutes later, and finally $1 \mathrm{~h}$ after the end of restraint for CORT radioimmunoassay. Following the functional challenge, animals received ADX surgery and were permitted $3 \mathrm{~d}$ recovery. On the second test day, animals $(n=4)$ were administered either $2 \mu \mathrm{l}$ vehicle or one of the three RU28362 doses from the functional test i.c.v. or $150 \mu \mathrm{g} / \mathrm{kg} \mathrm{RU} 28362$ i.p. (40\% HBC in saline, $0.3 \mathrm{ml}$ total volume). The $150 \mu \mathrm{g} / \mathrm{kg}$ i.p. dose is six times the effective dose for HPA suppression and has been demonstrated to fully saturate available brain GR (Ginsberg et al., 2003). One hour later, animals were perfused with buffer and fixative and brains collected for immunohistochemistry.

\section{Experiment 2: RU28362 versus CORT i.c.v.}

Animals were implanted with guide cannula in the right lateral ventricle and allowed a minimum of $7 \mathrm{~d}$ recovery. On the test day, animals received vehicle ( $2 \%$ ethanol in saline), $1 \mu \mathrm{g} \mathrm{RU} 28362$, or $1 \mu \mathrm{g}$ CORT (Steraloids Inc., Newport, RI, USA) in a total volume of $2 \mu \mathrm{l}(n=4)$. Following injection, rats were returned to their home cages. After $1 \mathrm{~h}$, subjects were placed in plastic restrainers for 30 min. Blood samples were collected via tail nick at the beginning and end of restraint for CORT radioimmunoassay. Following the functional challenge, animals received ADX surgery and were permitted $3 \mathrm{~d}$ recovery. On the second test day, animals were administered either $2 \mu \mathrm{l}$ vehicle $(n=3), 1 \mu \mathrm{g} \operatorname{RU} 28362(n=3)$, or $1 \mu \mathrm{g}$ CORT i.c.v. $(n=4) ; 150 \mu \mathrm{g} / \mathrm{kg}$ RU28362 $(n=2)$, or $150 \mu \mathrm{g} / \mathrm{kg}$ CORT i.p. $(n=2)$. One hour later, animals were perfused with buffer and fixative and brains collected for immunohistochemistry.

\section{Experiments 3 and 4: time course for $1 \mu \mathrm{g}$ RU28362 i.c.v. diffusion}

The third experiment was a short time course in which animals were implanted with guide cannula in the right lateral ventricle, $\mathrm{ADX}$, and allowed a minimum of $7 \mathrm{~d}$ recovery. On the test day, animals were administered $1 \mu \mathrm{g}$ RU28362 or $2 \mu \mathrm{l}$ vehicle $(40 \%$ $\mathrm{HBC}$ in saline) i.c.v., or $150 \mu \mathrm{g} / \mathrm{kg}$ RU28362 i.p. Vehicle- $(n=4)$ and i.p.- $(n=3)$ treated animals were perfused $1 \mathrm{~h}$ after injection, while RU28362 i.c.v.-treated groups were perfused with buffer and fixative $10(n=4), 30(n=4)$, or $60(n=4)$ minutes after injection. Brains and pituitaries were collected for immunohistochemistry.

In the fourth experiment, an extended time course, animals were implanted with guide cannula in the right lateral ventricle, ADX, and allowed a minimum of $7 \mathrm{~d}$ recovery. On the test day, animals were administered $1 \mu \mathrm{g} \mathrm{RU} 28362$ or $2 \mu \mathrm{l}$ vehicle (2\% ethanol in saline) i.c.v., or $150 \mu \mathrm{g} / \mathrm{kg} \mathrm{RU} 28362$ i.p. Vehicle- $(n=2)$ and i.p.- $(n=2)$ treated animals were perfused $1 \mathrm{~h}$ after injection, while the i.c.v. drug groups were perfused with buffer and fixative $60(n=4), 120(n=4)$, or $180(n=4)$ minutes after injection. Brains and pituitaries were collected for immunohistochemistry.

\section{Surgical procedures}

For both bilateral ADX and unilateral i.c.v. guide cannula surgeries, rats were fully anesthetized under ketamine $(50 \mathrm{mg} / \mathrm{kg})$ and 
xylazine $(10 \mathrm{mg} / \mathrm{kg})$ anesthesia or inhaled halothane. For i.c.v. surgeries, rats were fitted with a unilateral steel guide cannula (C315G-5UP/SPC; $6 \mathrm{~mm}$, Plastics One, Roanoke, VA, USA) in the right lateral ventricle (AP $-0.8 \mathrm{~mm}$ from bregma, $\mathrm{ML}$ $-1.4 \mathrm{~mm}$, DV $-3.8 \mathrm{~mm}$ from dura). A minimum of $7 \mathrm{~d}$ recovery was allowed between i.c.v. cannulation and testing. For recovery from ADX, a minimum of $3 \mathrm{~d}$ was permitted. Following ADX surgery, animals were maintained on $0.9 \%$ saline in lieu of tap water. ADX was confirmed by IHC (absence of nuclear GR immunostaining).

\section{I.c.v. injections}

I.c.v. injection of RU28362, CORT, or vehicle (40\% HBC in saline or $2 \%$ ethanol in saline) was performed manually. A side-by-side comparison revealed equivalent tissue distribution of RU28362 for either vehicle and no differential functional consequence of the two vehicles alone on HPA activity (data not shown). Although the HBC solution is highly effective at dissolving steroids (Pitha et al., 1986; Pitha, 1989), its high viscosity was undesirable for microinjections and thus we switched to the $2 \%$ ethanol in saline solution as a vehicle in later experiments. Injection solutions were drawn up by Hamilton syringe into PE50 tubing affixed to internal cannula (C315I/SPC; $7 \mathrm{~mm}$, Plastics One). Internal cannulas were then inserted into guide cannula of unanesthetized rats and $2 \mu \mathrm{l}$ total volume injection was delivered over approximately 90 seconds. Cannula placements were verified via observation of cannula tracts during brain sectioning.

\section{Immunohistochemistry}

Animals were deeply anesthetized with ketamine $(80 \mathrm{mg} / \mathrm{kg})$ and xylazine $(17 \mathrm{mg} / \mathrm{kg})$, after which $0.1 \mathrm{ml}$ heparin was injected into the right cardiac ventricle and allowed to circulate. Subjects were then exsanguinated by transcardiac perfusion of $0.01 \mathrm{M}$ PBS
$0.1 \%$ heparin $(\mathrm{pH} 7.4 ; 400 \mathrm{ml}$ in $10 \mathrm{~min}$ ) and fixed by perfusion of $4 \%$ paraformaldehyde in $0.01 \mathrm{M}$ phosphate buffer $(\mathrm{pH} 7.4 ; 400 \mathrm{ml}$ in $10 \mathrm{~min}$ ). Brains were postfixed in $4 \%$ paraformaldehyde/phosphate buffer for $48 \mathrm{~h}$ and were then sectioned $(50 \mu \mathrm{m}$ or $35 \mu \mathrm{m}$ thickness for brain or pituitary, respectively) on a Vibratome. PVN sections were collected at the rostral-caudal center of PVN (approximately bregma $-1.80 \mathrm{~mm}$ ). Hippocampus sections were collected at approximately bregma $-3.30 \mathrm{~mm}$. For the detection of $\mathrm{GR}$, floating sections were incubated overnight $\left(4^{\circ} \mathrm{C}\right)$ in the anti-GR antibody GR57 (PA511, Affinity Bioreagents, Golden, CO, USA) at a $1: 400$ dilution in $0.01 \mathrm{M}$ PBS (pH 7.5) plus $0.3 \%$ Triton $\mathrm{X}-100$, and $1.5 \%$ normal goat serum. The GR57 antibody was raised against a 22 amino acid peptide sequence (346-367) taken from the human GR and located in the regulatory region of GR. Previous characterization indicates that the GR57 antibody recognizes both the unactivated and activated form of the receptor (Cidlowski et al., 1990). Following incubation in primary antibody, sections were rinsed in PBS and incubated for $1 \mathrm{~h}$ in biotinylated secondary antibody at a 1:400 dilution (Vector Laboratories, Burlingame, CA, USA). Immunoreactivity was detected with the Vectastain ABC method (Vector Laboratories), using diaminobenzidine $(0.5 \mathrm{mg} / \mathrm{ml}$ Tris $)$ and $0.005 \%$ nickel ammonium sulfate as chromagen. Sections were then mounted on slides, dried, delipidized, and coverslipped. Sections were photographed using a light microscope (Olympus Corporation, Melville, NY, USA; Model BX61) and digital camera and processed with Olympus Microsuite software (Soft Imaging, Lakewood, CO, USA).

\section{Immunohistochemistry GR occupancy rating}

Relative GR occupancy was estimated based on the amount of punctate nuclear immunostaining present upon visual inspection of photomicrographs. Photomicrographs of brain sections were captured using a light microscope and Olympus Microsuite

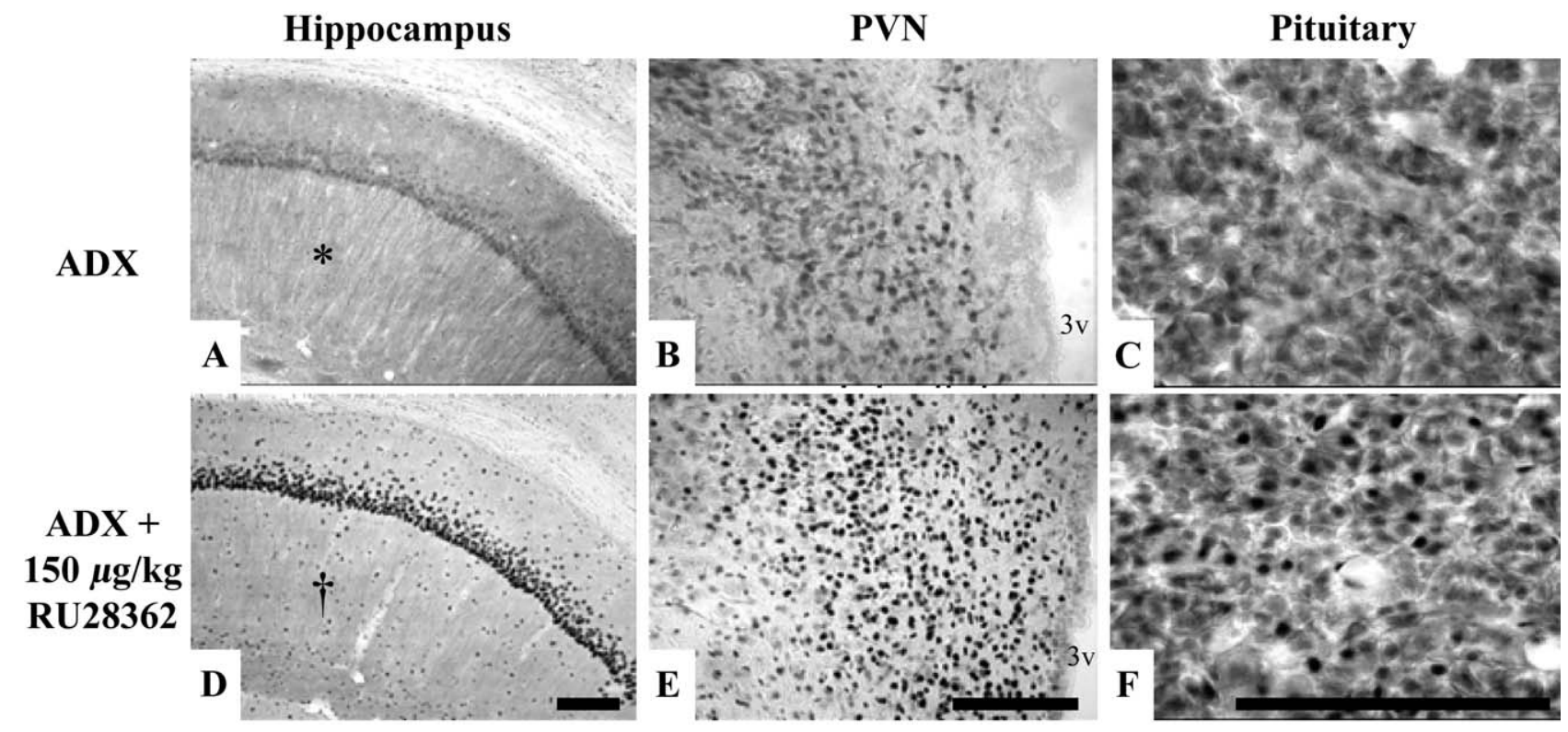

Fig. 1. Representative images of nuclear versus cytoplasmic GR immunostaining. The above pictures demonstrate the two extremes of the GR occupancy rating system used herein. The top three panels are images taken from hippocampus, PVN, and pituitary of ADX animals. The lower panels show the same regions following a $1 \mathrm{~h}$ pretreatment of ADX rats with $150 \mu \mathrm{g} / \mathrm{kg} \mathrm{RU} 28362$ delivered intraperitoneally. Sections depicted in the top row would be scored 0 ; those on the bottom row represent a score of 4 . Hippocampal pyramidal cells in CA1 show diffuse GR immunostaining (A) in the ADX animal. GR is evident in the cell bodies as well as in the apical dendrites $\left({ }^{*}\right)$. Following steroid treatment, punctate nuclear immunostaining and decreased immunostaining in the apical dendrites $\left(^{+}\right)$indicate the presence of activated GR (D). In the PVN, nuclear immunostaining can be seen following RU28362 administration (E) but not in the ADX animal (B). Activated GR is observed in the anterior pituitary in cells expressing GR only after RU28362 administration (C and F). Scale bar $=0.2 \mathrm{~mm}$. 
software. Raters trained to criterion (inter-rater-reliability $>0.8$ ), then blindly assigned ratings of 0 (no nuclear immunostaining) to 4 (maximal nuclear immunostaining) to three to five sections per brain (Fig. 1). Diffusion of RU28362 away from the third ventricle was scored $0-3$ with 0 representing no GR occupancy and 3 representing GR occupancy throughout the lateral extent of the PVN (Fig. 2). Each integer increase represents approximately $0.25 \mathrm{~mm}$ away from the third ventricle. Scores were averaged for each brain and compared with ANOVA

\section{CORT measurement}

CORT plasma concentration was measured by radioimmunoassay. Plasma samples were diluted 1:50 in $0.01 \mathrm{~m}$ PBS and were heated at $75^{\circ} \mathrm{C}$ for $1 \mathrm{~h}$ to inactivate corticosteroid-binding globulin. Samples were incubated in duplicate overnight at $4{ }^{\circ} \mathrm{C}$ with rabbit antiserum raised against CORT-21-hemisuccinate BSA (B3-163; Endocrine Sciences, Inc., Calabasas Hills, CA, USA) and [1,2,6, 7-3H]CORT (NEN Life Science Products, Boston, MA, USA). Antibody-bound CORT was separated from free steroid by centrifugation after addition of dextran-coated activated charcoal. Coefficients of variation between and within assays were less than $10 \%$. Assay sensitivity was approximately $0.5 \mu \mathrm{g} / 100 \mathrm{ml}$.

\section{Statistical analysis}

Data were initially analyzed for each experiment with separate one way (GR immunostaining measures) or two way (plasma CORT

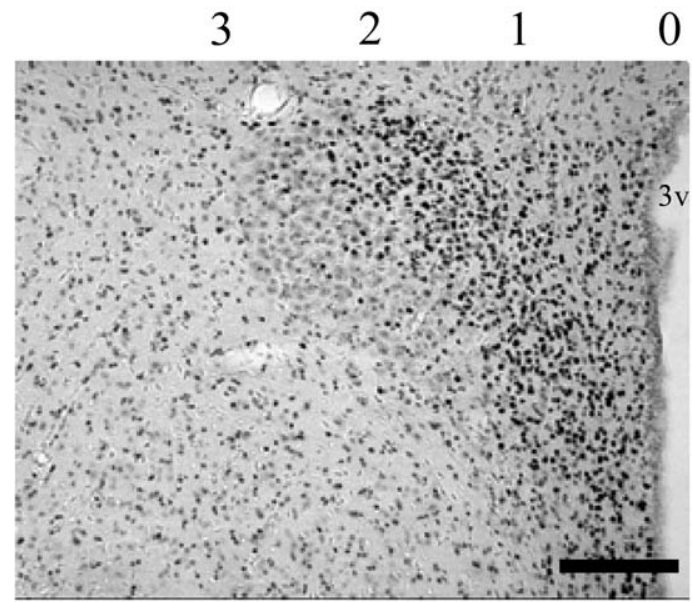

PVN 1 hour after $150 \mu \mathrm{g} / \mathrm{kg}$ RU28362 IP

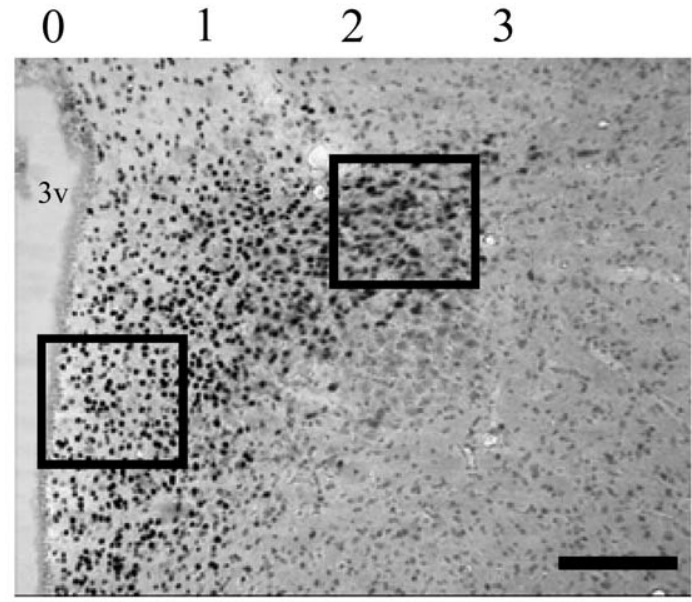

PVN 10 minutes after $1 \mu \mathrm{g}$ RU28362 ICV

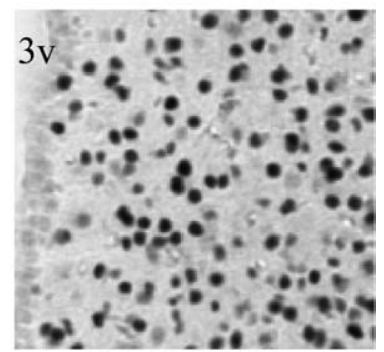

Medial PVN

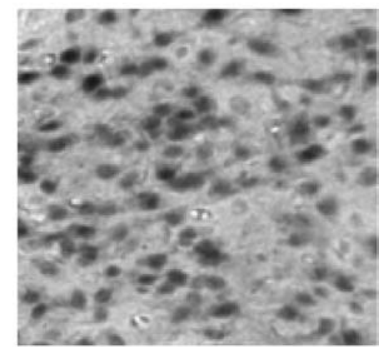

Lateral PVN

Fig. 2. Pictured above are PVN sections demonstrating our scoring method for lateral extent of GR occupancy in the PVN. The numbers above the photomicrographs represent the ratings used to quantify diffusion away from the CSF into the PVN. Each integer increase represents approximately $0.25 \mathrm{~mm}$ away from the third ventricle. The left panel is from an ADX animal $1 \mathrm{~h}$ after $150 \mu \mathrm{g} / \mathrm{kg} \mathrm{RU} 28362$ i.p. Nuclear GR immunostaining is observed at all areas of the PVN and would receive a score of 3. Above right is a section from an ADX animal $10 \mathrm{~min}$ after i.c.V. administration of $1 \mu \mathrm{g}$ RU28362. Punctate GR immunostaining can be observed periventricularly, but is not evident in more lateral aspects of the PVN. This section would be scored a 1. At right are magnifications of the two boxes pictured in the above right section. The upper panel shows punctate GR nuclear immunostaining adjacent to the third ventricle. In the lower panel, diffuse cytoplasmic GR immunostaining indicates that RU28362 has not penetrated the more lateral aspect of the PVN. Scale bar $=0.2 \mathrm{~mm}$. 
measures) analysis of variance (ANOVA) tests, followed by post hoc tests (Fisher's least significant difference test). An alpha-level of $P \leq 0.05$ was used to determine statistical significance, and, where relevant, exact significance values are reported. A computer statistical package (Statview v. 4.51; Abacus Concepts, Berkeley, CA, USA) was used to perform the analyses. Data presented in the figures represent group means \pm S.E.

\section{RESULTS}

\section{Dose response for i.c.v. RU28362}

In order to examine the parameters of centrally mediated glucocorticoid negative feedback, we injected into the lateral ventricle three different doses of the GR agonist $\mathrm{RU} 28362(0.005,0.1$ and $1 \mu \mathrm{g}) 1 \mathrm{~h}$ prior to the onset of 60 min of restraint stress. Doses were chosen to provide varying degrees of GR activation and consequently varying degrees of HPA suppression. The $1 \mu \mathrm{g}$ dose was predicted to be a high i.c.v. dose as previous work indicated that a $25 \mu \mathrm{g} / \mathrm{kg}$ dose $(\sim 10 \mu \mathrm{g}$ total/rat) delivered i.p. was sufficient to suppress stress-induced HPA activation (Fig. 3A; reprinted with permission) (Ginsberg et al., 2003). The rat brain accounts for approximately $0.7 \%$ of total body mass (Mink et al., 1981) and thus, assuming equal distribution throughout brain, the $1 \mu \mathrm{g}$ i.c.v. injection should theoretically result in brain concentrations roughly 10 times as concentrated as with a $25 \mu \mathrm{g} / \mathrm{kg}$ i.p. RU28362 dose. Serial blood samples were collected from each animal at four time points $(0,30$, and 60 min after restraint onset and $60 \mathrm{~min}$ after the end of restraint). Plasma CORT levels were determined and are displayed in Fig. 3B. No drug effect on HPA axis suppression was observed at any of the doses, although there was a trend toward a faster recovery at the final time point in the $1 \mu \mathrm{g}$ group $[F(3,22)=1.6$; $P=0.21]$.

Due to the absence of a functional effect of any of the i.c.v. administered doses, we explored the extent to which the steroid distributes throughout the brain after i.c.v. injection. Surprisingly, with all three i.c.v. RU28362 doses, nuclear immunostaining was primarily restricted to periventricular tissue. For example, there was visible GR nuclear immunostaining in tissue surrounding the third ventricle, including the most medial portion of the PVN, as well as the most medial portion of the CA1 region of the hippocampus adjacent to the dorsal third ventricle. In contrast, there was no evidence for nuclear GR immunostaining in tissue more distal to the ventricles such as the majority of the hippocampus, cortex, striatum, lateral hypothalamus or amygdala (Fig. 4). The high i.p. dose of RU28362 caused significant nuclear GR immunostaining in all brain areas examined (Fig. 1), whereas animals receiving RU28362 i.c.v. looked identical to ADX- or vehicle-treated animals with the exception of nuclear GR immunostaining in periventricular areas (Figs. 1, 2 and 4). In medial PVN, there was not a main effect of treatment group $[F(4,15)=2.36 ; P=0.10]$, but post hoc tests indicated significantly less nuclear immunostaining in the vehicle group as compared with the $0.005 \mu \mathrm{g}$ and $0.1 \mu \mathrm{g}$ i.c.v. doses as well as the $150 \mu \mathrm{g} / \mathrm{kg}$ i.p. dose (Fig. 5A). A main effect for treatment group was observed for the lateral extent of GR occupancy in the PVN $[F(4,14)=4.68 ; P=0.01)$. The two higher i.c.v. drug doses as well as the i.p. injection all resulted in significantly higher occupancy ratings than the vehicle group (Fig. 5B). In hippocampus (Fig. 5C), little to no GR
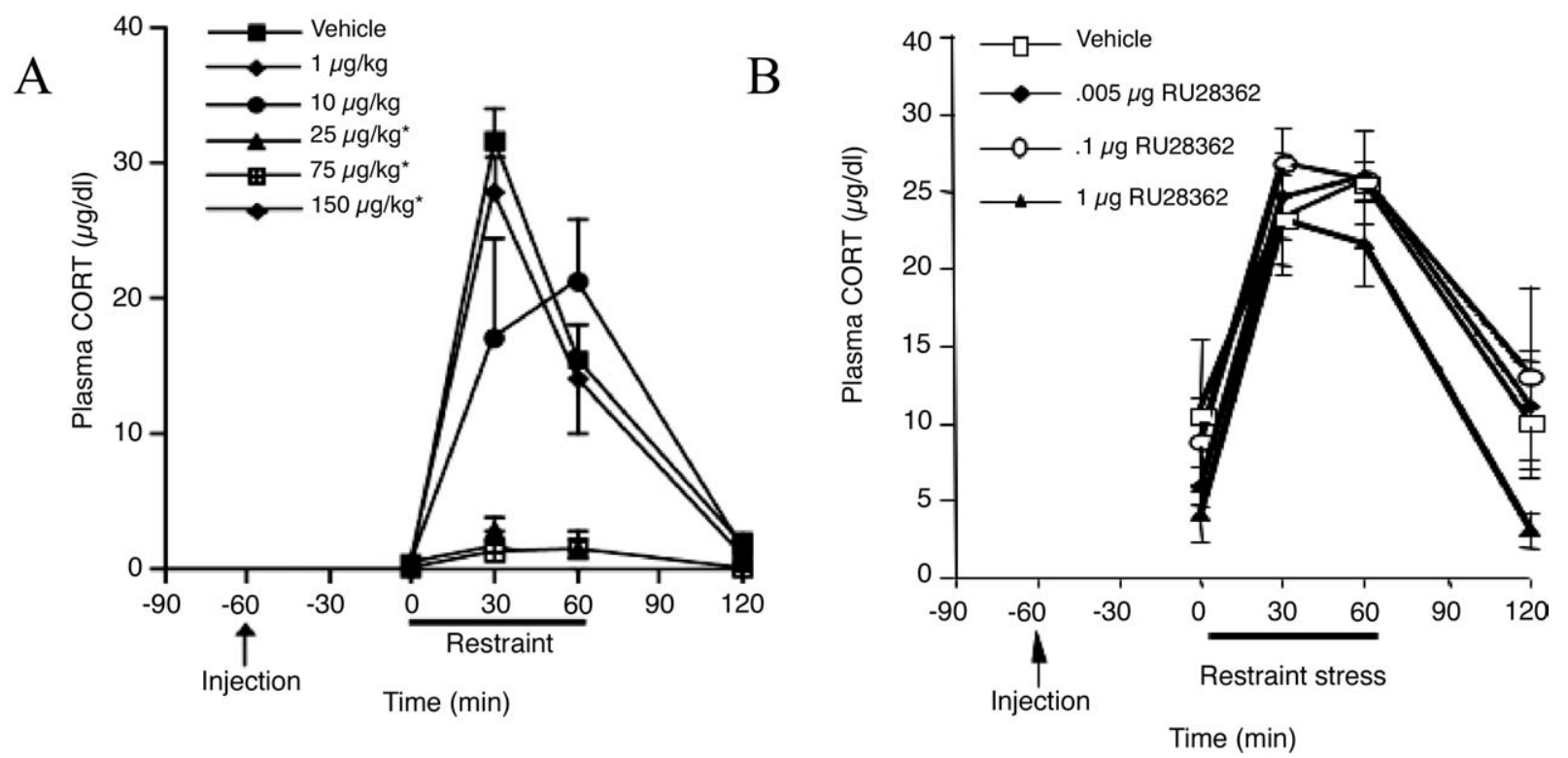

Fig. 3. RU28362 suppresses stress-induced HPA activation when delivered i.p., but not i.c.v. In the intact animal, 1 h pretreatment of i.p. RU28362 suppressed restraint stress-induced CORT production in a dose dependent fashion (A; $n=4-8 ;{ }^{*}$ significant difference from vehicle at 30,60 min, $P<0.05$; reprinted with permission from Ginsberg et al., 2003). Three doses of RU28362 (0.005, 0.1 , and $1 \mu$ g) delivered i.c.v. fail to suppress HPA activation (B; $n=6-7$ ). I.c.v. injections delivered $1 \mathrm{~h}$ prior to 60 min restraint stress do not blunt restraint stress-induced CORT production. Serial blood samples were collected via tail nick at $0,30,60,90$, and 120 min after stressor onset. Plasma CORT concentrations were determined by RIA. 


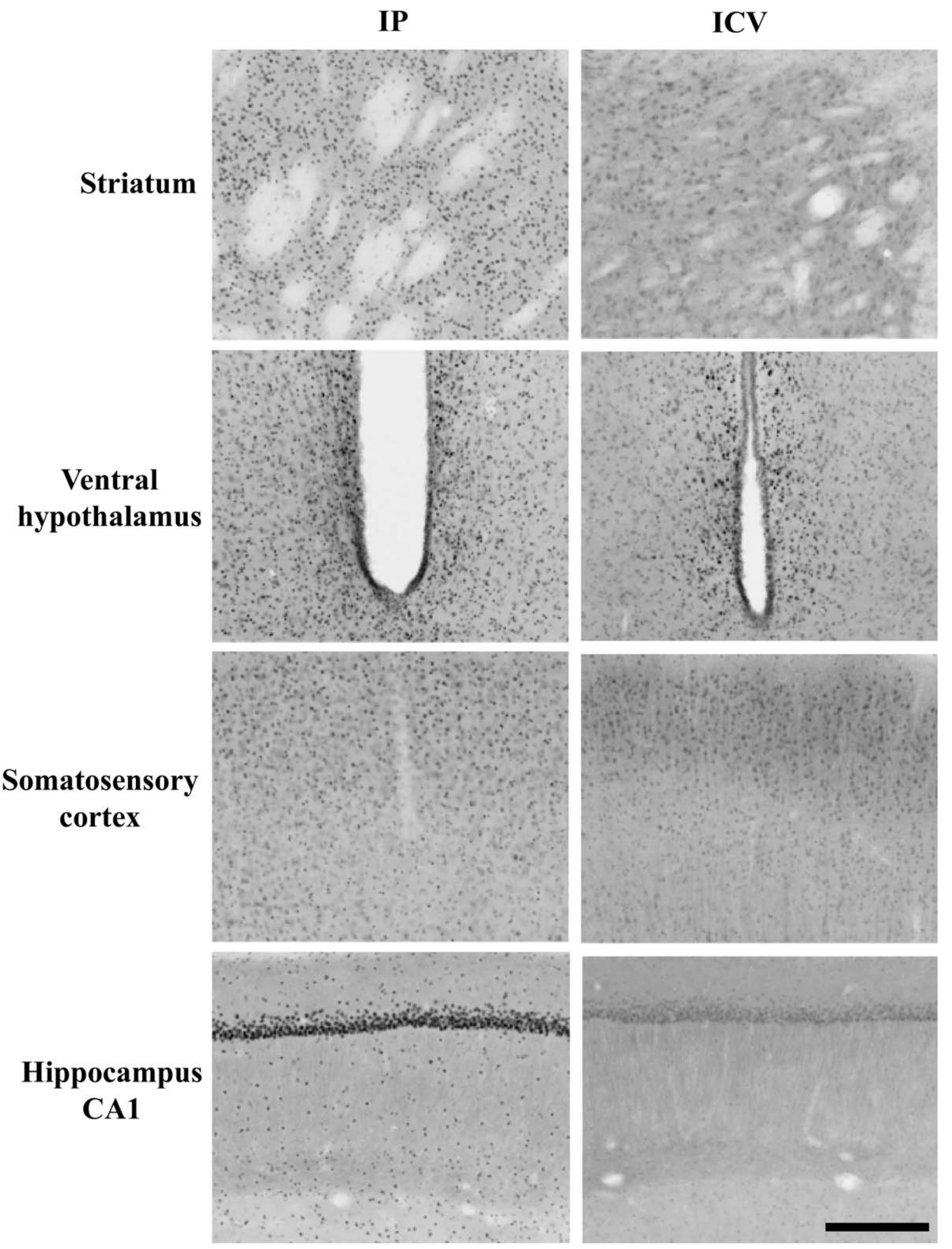

Fig. 4. GR immunostaining following i.p. versus i.c.v. injection of RU28362. The photomicrographs in the left column show four brain regions in ADX animals $1 \mathrm{~h}$ after $150 \mu \mathrm{g} / \mathrm{kg}$ RU28362 delivered i.p. On the right are the same regions from ADX animals $1 \mathrm{~h}$ after a $1 \mu \mathrm{g}$ RU28362 i.c.v. injection. With the exception of periventricular areas, all regions examined showed extensive nuclear GR immunostaining with i.p. delivery, but largely cytoplasmic immunostaining following i.c.v. drug administration. Scale bar $=0.2 \mathrm{~mm}$.

nuclear immunostaining was observed following any of the i.c.v. doses, whereas the i.p. treatment caused sig- nificant GR occupancy $[F(4,15)=13.43 ; \quad P<0.0001]$ (Fig. 5C). 
A

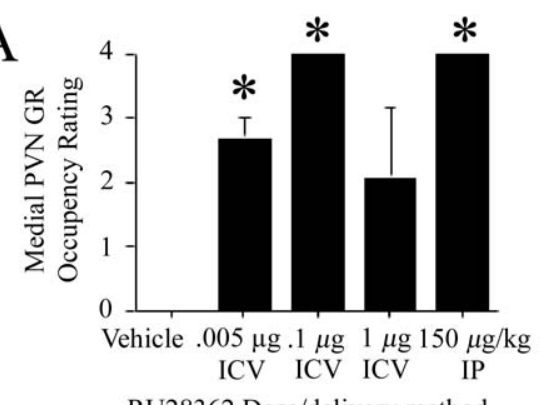

RU28362 Dose/delivery method
$\mathrm{B}$

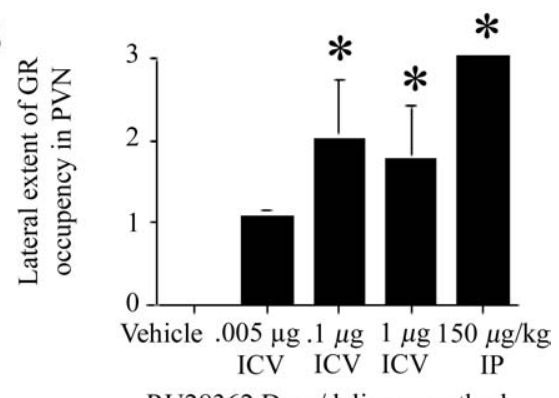

$\mathrm{C}$

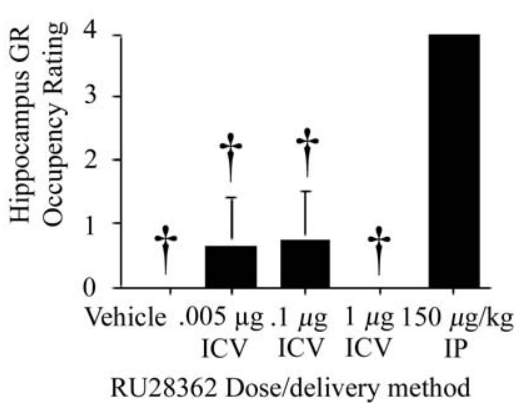

Fig. 5. GR PVN and hippocampal occupancy profile for three doses of RU28362. RU28362 $(0.005 \mu \mathrm{g}, 0.1 \mu \mathrm{g}$, and $1 \mu \mathrm{g})$ was delivered i.c.v. $1 \mathrm{~h}$ prior to kill to ADX animals $(n=4)$. In the medial PVN, all three doses of RU28362 delivered i.c.v. produce some GR occupancy (A). However, diffusion of the drug away from the third ventricle was limited (B). None of the i.c.v. drug injections significantly occupied hippocampal GR (C). In both hippocampus and medial PVN (A and B), the $150 \mu \mathrm{g} / \mathrm{kg}$ i.p. injection resulted in maximally occupied GR with extensive nuclear staining observed throughout the PVN (C) ( ${ }^{*}$ significant difference from vehicle; ${ }^{\dagger}$ significant difference from i.p., $\left.P<0.05\right)$.

\section{RU28362 versus CORT i.c.v.}

To examine whether the limited tissue diffusion of drug after i.c.v. injection was idiosyncratic to RU28362, we compared the abilities of i.c.v. CORT and RU28362 to (1) suppress stress-induced HPA axis activity and (2) diffuse away from the injection site. Neither drug affected stress-induced HPA axis activation as both groups of drug-treated rats exhibited equivalent stress-induced CORT elevations as vehicle-treated rats (Fig. 6) $[P>0.05]$.

After stress hormone response testing, animals were adrenalectomized and allowed $3 \mathrm{~d}$ to clear endogenous CORT. After recovery, animals received a second series of injections to determine the GR occupancy profile for the respective conditions. Both drugs exhibited similar patterns of limited diffusion from the injection site. As in the first study, medial PVN GR was readily activated whereas more lateral areas of the PVN showed little to no nuclear immunostaining (Fig. 7A and B). In medial PVN, all groups receiving drug (CORT or RU28362) demonstrated significantly more nuclear immunostaining than the vehicle group $[F(4,9)=5.84 ; P=0.01]$. CORT appeared to diffuse slightly more readily as CORT-treated animals had higher ratings than their $\mathrm{RU} 28362$ counterparts in both i.c.v. and i.p. conditions. There was also a significant drug effect on lateral diffusion into the $\operatorname{PVN}[F(4,9)=11.18 ; P<0.01]$. Post hoc tests revealed significant differences between i.c.v. RU28362 and both drugs i.p. The difference between i.c.v. CORT and i.p. CORT also reached significance. In the hippocampus, no GR activation was observed with i.c.v. drug treatment (7C). I.c.v.-treated animals were indistinguishable from animals that received vehicle. I.p. injection

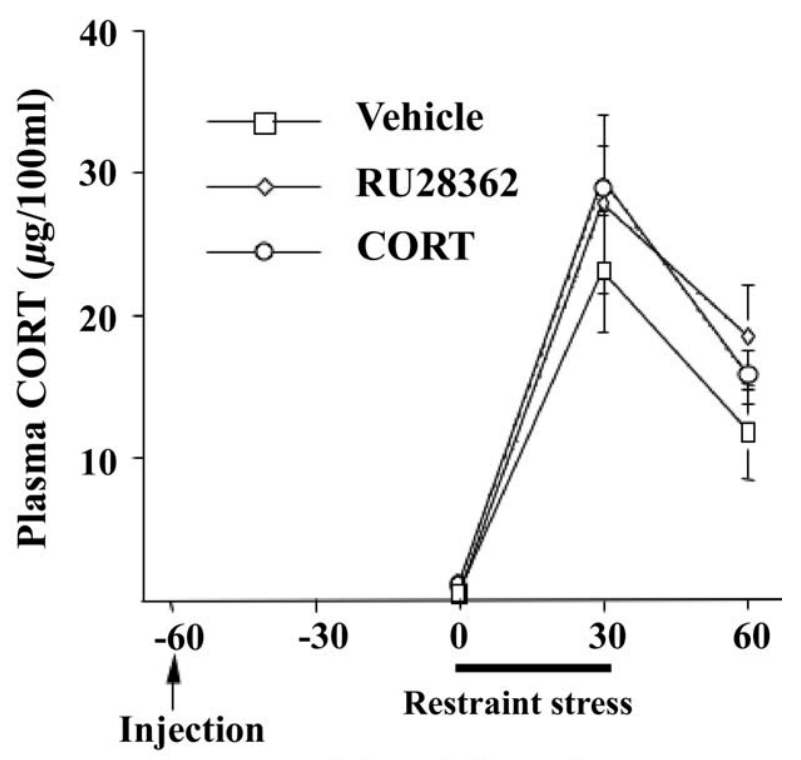

Time (minutes)

Fig. 6. Neither CORT $(1 \mu \mathrm{g})$ nor RU28362 $(1 \mu \mathrm{g})$ delivered i.c.v. $1 \mathrm{~h}$ prior to the onset of restraint stress suppresses HPA axis activity $(n=4)$. Serial blood samples were collected via tail nick at 0,30 , and 60 min after stressor onset. Plasma CORT concentrations were determined by RIA. 


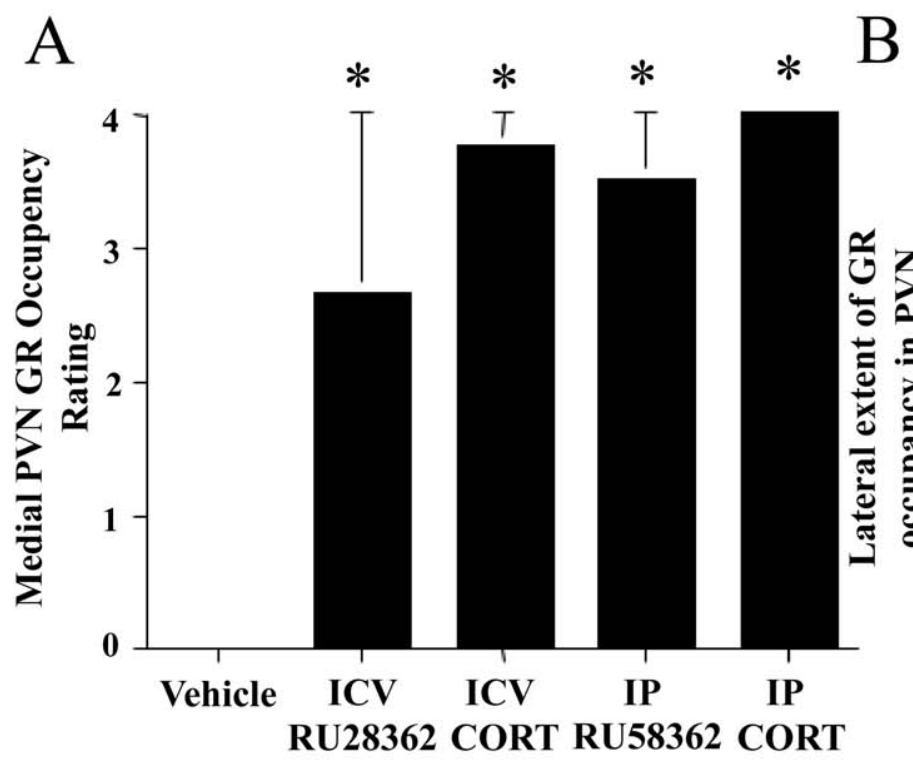

Drug/delivery method

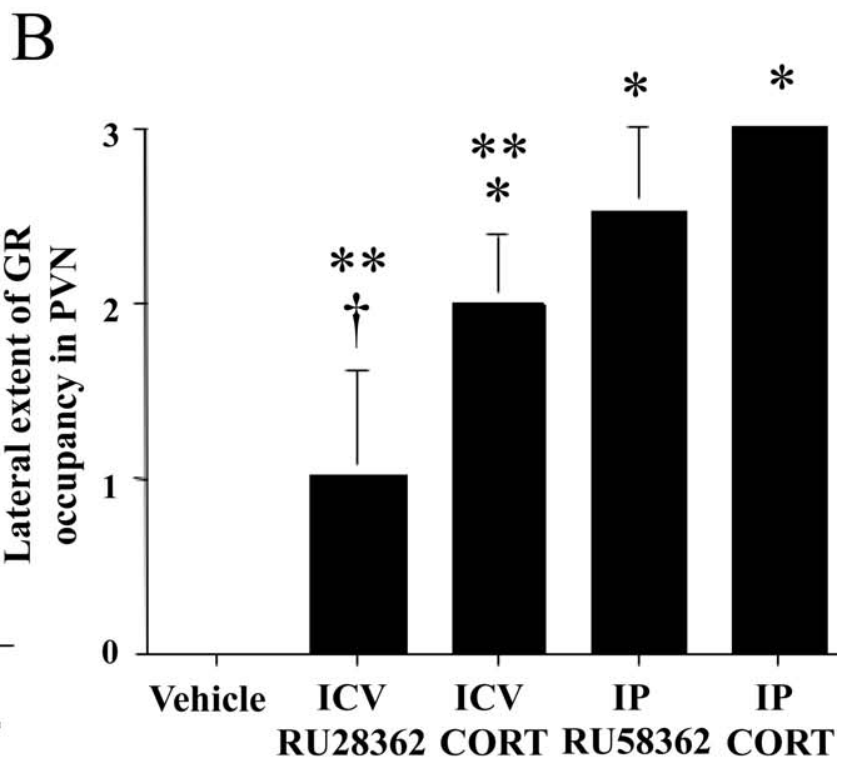

Drug/delivery method

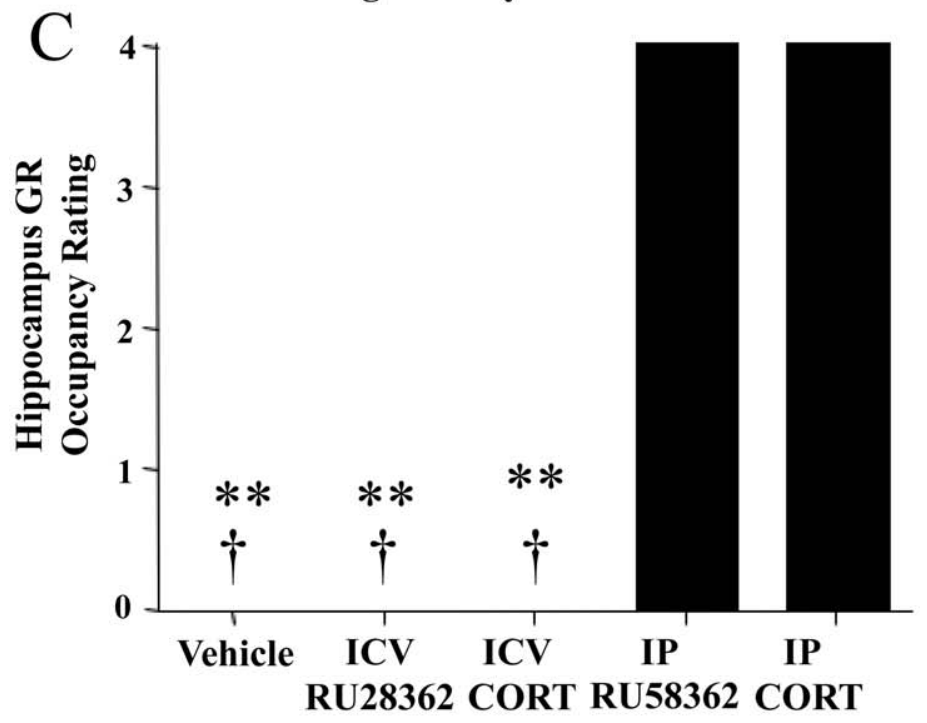

Drug/delivery method

Fig. 7. GR occupancy profile for CORT or RU28362 delivered i.c.v. $(1 \mu \mathrm{g} ; n=4)$ or i.p. $(150 \mu \mathrm{g} / \mathrm{kg} ; n=2)$. In ADX animals, $1 \mathrm{~h}$ after i.c.v. drug administration, GR in the medial PVN was occupied (A and B), whereas there was no detectable occupancy in the hippocampus (C). In the PVN, it appears that CORT i.c.v. was able to diffuse more laterally than RU28362 (B), but this difference was not reflected in a greater ability to suppress the CORT (see Fig. 6) ( ${ }^{*}$ significant difference from vehicle; ${ }^{\dagger}$ significant difference from i.p. RU28362; ${ }^{* *}$ significant difference from i.p. CORT; $P<0.05$ ).

of either drug, however, resulted in maximal nuclear immunostaining $(P<0.0001)$.

\section{Time course for $1 \mu \mathrm{g}$ RU28362 diffusion}

Because of the observed restriction of nuclear GR immunostaining to periventricular tissue $1 \mathrm{~h}$ following i.c.v. CORT or RU28362 administration, we became interested in the possible temporal requirements for i.c.v. drug diffusion. For these experiments, $1 \mu \mathrm{g}$ RU28362 was delivered i.c.v. and animals were killed at several time points following drug administration. In addition to the brain regions examined in the previous study, we also collected pituitar- ies as a measure of diffusion of the drug away from the brain.

The first experiment was a short time course designed to determine whether GR had been activated and then returned to the cytoplasm during the interval between i.c.v. injection and kill. Animals were killed 10, 30, or 60 min after i.c.v. injection. In the medial PVN, our GR occupancy rating was near maximal by $10 \mathrm{~min}$ after i.c.v. infusion (Fig. 2, Fig. 8A). An overall effect of group was noted $[F(4,12)=7.59 ; P<0.01]$ with significant differences found between the vehicle-treated group and all other groups. Lateral areas of the PVN did not demonstrate significant 

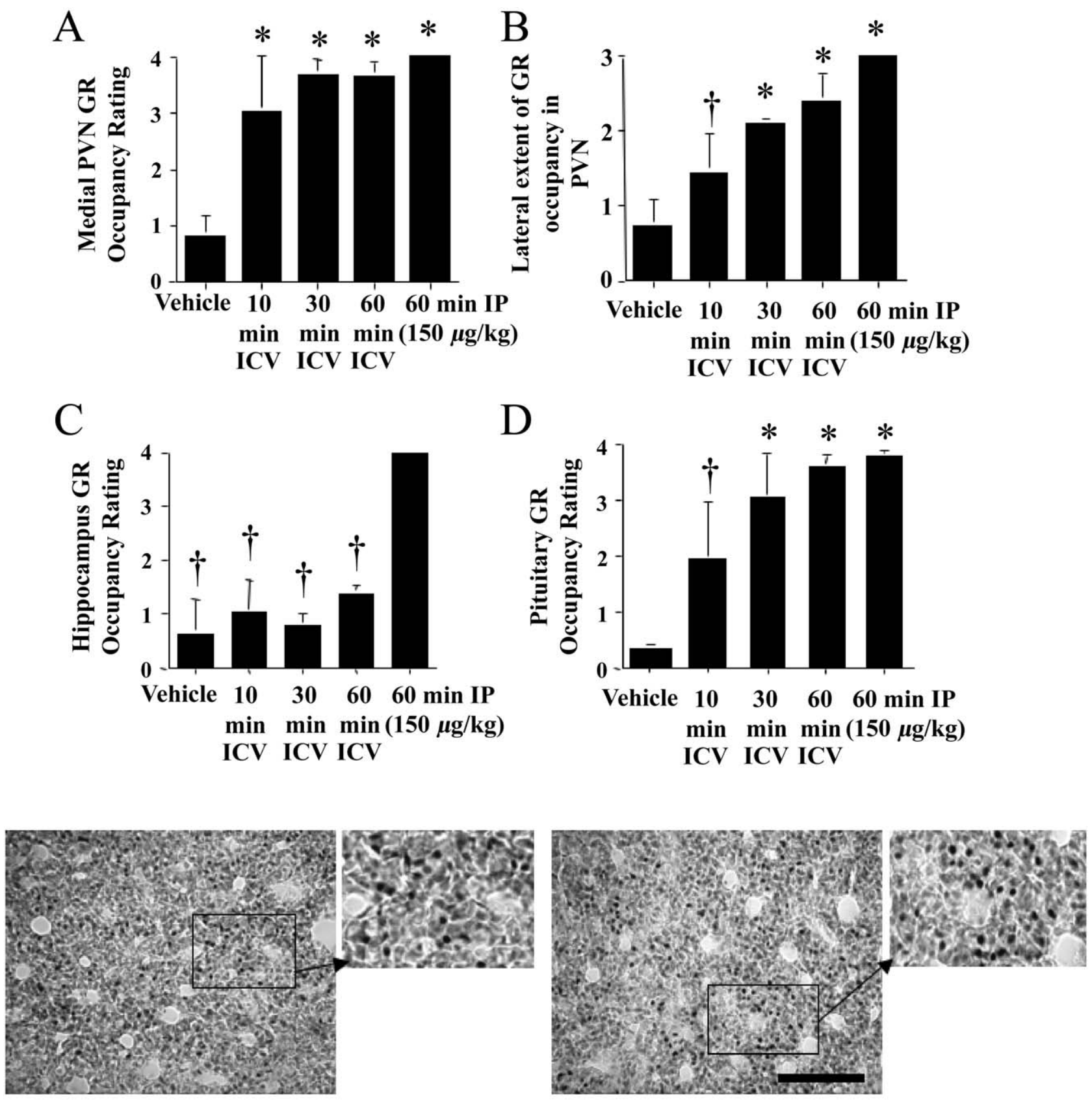

Pituitary 1 hour after $1 \mu \mathrm{g}$ ICV RU28362

Pituitary 1 hour after $150 \mu \mathrm{g} / \mathrm{kg}$ IP RU28362

Fig. 8. Time course for RU28362 activation of GR in PVN, hippocampus, and pituitary following i.c.v. delivery $(n=3-4)$. ADX animals received $1 \mu \mathrm{g}$ i.c.v. RU28362 injections. Ten minutes later, activated GR was observed in the medial PVN (A). After 30 and 60 min, greater GR occupancy in more lateral areas of the PVN indicates the slow diffusion of RU28362 from the ventricle (B). In the hippocampus, no appreciable GR activation was observed at any time point after i.c.v. infusion (C). In the anterior pituitary, some GR activation was detected at 10 min with increasing translocation noted at 30 and $60 \mathrm{~min}$ after i.c.v. infusion (D). In all cases, the $150 \mu \mathrm{g} / \mathrm{kg}$ i.p. dose resulted in maximal GR occupancy in all regions ( ${ }^{*}$ significant difference from vehicle; ${ }^{\dagger}$ significant difference from i.p., $\left.P<0.05\right)$. Below are pictured pituitaries $1 \mathrm{~h}$ after i.c.v. $(1 \mu \mathrm{g})$ or i.p. $(150 \mu \mathrm{g} / \mathrm{kg})$ injection. Nuclear immunostaining following i.c.v. injection (left) is nearly identical to the high dose i.p. (right). Scale bar $=0.2 \mathrm{~mm}$.

GR nuclear translocation until the 30 and 60 min time points (Fig. 8B). A main effect of treatment group was observed $[F(4,13)=6.69 ; P<0.01]$. As in the previous study, little to no hippocampal GR activation was noted except in the i.p. drug-treated group (Fig. 8C) accounting for an overall significant drug treatment effect $[F(4,14)=$ 5.87; $P<0.01]$. In the pituitary, there was a main effect of treatment group $[F(4,14)=7.61 ; P<0.01]$, and GR occupancy by drug was significantly greater than vehicle by 30 min (Fig. 8D). Photomicrographs depict pituitaries from 

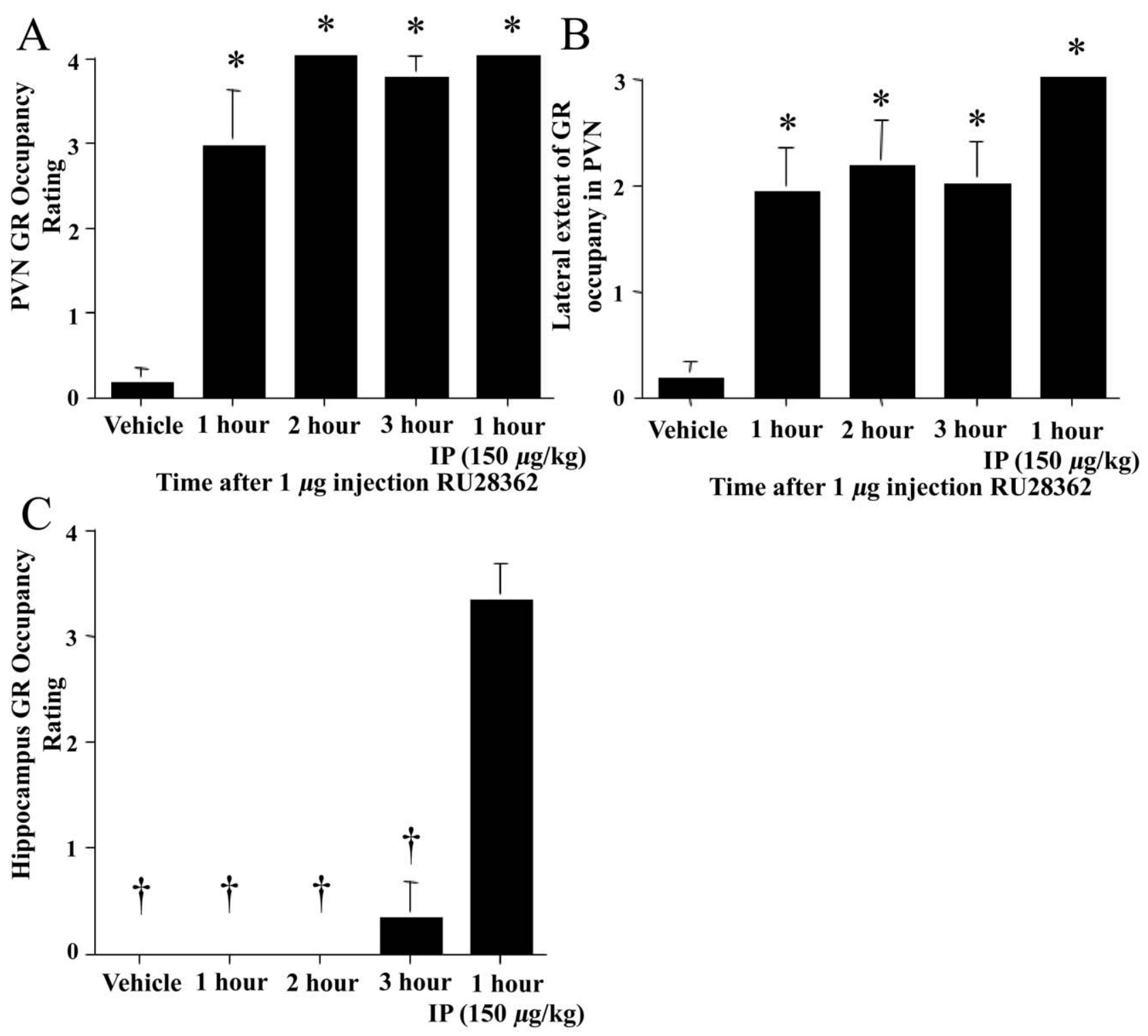

Time after $1 \mu \mathrm{g}$ injection RU28362

Fig. 9. Extended time course of PVN and hippocampal GR occupancy in ADX animals following $1 \mu \mathrm{g}$ RU28362 i.c.v. injection ( $n=3-4)$. In the PVN, RU28362 occupies GR in medial areas at all three time points (A and B). In hippocampus, no GR occupancy is noted at either the $1 \mathrm{~h}$ or $2 \mathrm{~h}$ time points. At $3 \mathrm{~h}$, some nuclear staining is observed $(C)\left({ }^{*}\right.$ significant difference from vehicle; ${ }^{\dagger}$ significant difference from i.p., $\left.P<0.05\right)$.

animals administered $1 \mu \mathrm{g}$ RU28362 i.c.v. or $150 \mu \mathrm{g} / \mathrm{kg}$ RU28362 i.p. (Fig. 8).

In the second time-course experiment, animals were killed 1, 2, or $3 \mathrm{~h}$ after i.c.v. injection of $1 \mu \mathrm{g} R U 28362$ in order to determine whether the infused steroid would ultimately occupy a greater extent of brain GR. In the medial $P V N$, there was a main effect of treatment group $[F(4,11)=11.17 ; P<0.01]$. The previously observed GR occupancy at $1 \mathrm{~h}$ after RU28362 was sustained throughout the $3 \mathrm{~h}$ of the time course (Fig. 9A). However, it does not appear that the drug was able to diffuse any further from the third ventricle between 1 and $3 \mathrm{~h}$ post-injection (Fig. $9 B$ ). ANOVA revealed a main effect for treatment group on lateral extent of $\mathrm{GR}$ occupancy $[F(4,10)=4.13 ; P=0.03]$ with significant differences observed between the vehicle group and all other groups. Hippocampal GR was largely cytoplasmic at all three time points following i.c.v. injection (Fig. 9C). A main effect of group was noted $[F(4,12)=$ 34.56; $P<0.0001$ ] with significant differences observed between the i.p. group and all other groups.

\section{DISCUSSION}

We present here a technique for tracking drug diffusion following i.c.v. injection. Our data indicate that i.c.v. delivery of the GR agonist RU28362 results in very limited diffusion from the ventricular system into surrounding brain tissue. Though we were initially puzzled 
by the inability of an i.c.v. injection of a GR agonist to suppress stress induced HPA axis activity, it appears that insufficient delivery to critical sites of action is a likely explanation.

In the first experiment, three doses of RU28362 delivered i.c.v. (0.005, 0.1 and $1 \mu \mathrm{g})$ failed to blunt stress induced HPA axis activation (Fig. 3). Following ADX, animals were again presented with vehicle, one of the three doses i.c.v., or $150 \mu \mathrm{g} / \mathrm{kg}$ RU28362 i.p. One hour after injection, brains were collected for GR immunostaining. All three i.c.v. doses caused significant nuclear immunostaining in medial PVN (to approximately $0.4 \mathrm{~mm}$ lateral of the ventricle), but little to none in other brain regions such as cortex, striatum or dorsal hippocampus (Fig. 4). On the other hand, i.p. injection of RU28362 produced a marked and uniform pattern of nuclear GR immunostaining throughout the brain.

We considered the possibility that the observed poor RU28362 delivery might be idiosyncratic to our vehicle or drug. We were able to rule out a vehicle effect by comparing delivery of RU28362 in 40\% HBC to RU28362 dissolved in ethanol and then into saline. Manipulating the vehicle had no effect on the pattern of nuclear GR immunostaining. In both conditions, we saw substantial nuclear GR accumulation in medial PVN, but none in the dorsal hippocampus.

To rule out the possibility that RU28362 was selectively excluded from brain, we compared the abilities of CORT and RU28362 to occupy brain GR following i.c.v. administration. First, RU28362 and CORT were directly compared within the same experiment to determine whether $1 \mu \mathrm{g}$ i.c.v. CORT might suppress stress induced HPA activity. Neither CORT nor RU28362 produced a suppressive effect compared with vehicle (Fig. 6). Again, comparable limited nuclear GR immunostaining was observed following administration of either drug. Both drugs caused activation of GR in the medial PVN, but not in hippocampus (Fig. 7). RU283632 binds GR with approximately 10-fold greater affinity than CORT (Reul and de Kloet, 1985; Jacobson et al., 1993), but this does not appear to differentially affect GR translocation with a $1 \mu \mathrm{g}$ dose.

The final two experiments examined the time course for RU28362 penetration into PVN and hippocampus. Further, pituitaries were collected for immunostaining to determine the ability of the drug to activate hypophyseal GR. In the first experiment, GR in the medial PVN was activated within 10 minutes of i.c.v. injection and appeared to diffuse farther from the third ventricle at each of the later time points (Fig. 8). The i.c.v. injection also caused significant occupancy of GR within the pituitary. This was especially true at the later time points. By 60 minutes, pituitary GR nuclear immunostaining in i.c.v.-injected animals and high dose i.p. animals was nearly indistinguishable (Fig. 8). In the longer time course, GR activation in the PVN appears to plateau by $1 \mathrm{~h}$ after i.c.v. injection. No GR activation was observed in the hippocampus until perhaps the $3 \mathrm{~h}$ time point; however, even then the low level of GR nuclear immunostaining was not significantly different from control.

\section{I.c.v. considerations}

Although widespread brain diffusion of CORT has been demonstrated following chronic i.c.v. infusion (Laugero et al., 2002), it is perhaps not surprising that acute i.c.v. injection is an inefficient drug delivery method when one considers drug diffusion rates and the dynamics of CSF flow. In aqueous solution, the diffusion rate for a small molecule is approximately $5 \times 10^{-6} \mathrm{~cm}^{2} / \mathrm{s}$ or $500 \mu \mathrm{m}^{3}$ in $4 \mathrm{~h}$ (Hazel and Sidell, 1987). In vivo, small molecules migrate even more slowly, as estimates for diffusion rates in brain are approximately $40 \%$ of those in water (Fenstermacher and Davson, 1982; Fenstermacher and Kaye, 1988). Tracing the flow of CSF from production to its reabsorption into the bloodstream provides further explanation of the observed limited delivery. CSF is produced by the choroid plexus in the lateral ventricles and flows to (1) the third ventricle, (2) the fourth ventricle via the cerebral aqueduct, (3) cisterns at the ventral brain surface (likely allowing for delivery to pituitary as it is surrounded by the suprasellar cistern), (4) the superior saggital sinus via the surface of the cerebellum, and (5) the arachnoid villi where it is reabsorbed into the bloodstream. CSF is produced and reabsorbed rapidly; in rat complete CSF turnover rate takes place in about an hour (Davson, 1996). In mouse, the time required for $50 \%$ of an i.c.v. injection of leptin to reach the peripheral bloodstream has been estimated to be approximately 73 min (Maness et al., 1998). In another demonstration of rapid clearance from the CSF, radiolabeled IGF-I was shown to be $80 \%$ depleted from CSF within 30 min of i.c.v. injection with significant accumulation of radiolabeling noted only in periventricular brain areas (Nagaraja et al., 2005). Thus, several researchers have concluded that direct injection into the ventricular system is largely equivalent to a slow i.v. injection (Billiau et al., 1981; Crawley et al., 1991; de Lange et al., 1994; Pardridge, 1997; Turnbull and Rivier, 1998).

Despite the rapid clearance from the ventricular system, we invariably observed significant nuclear GR immunostaining in the PVN adjacent to the third ventricle. Previous studies utilizing radiolabeled sucrose (Ghersi-Egea et al., 1996) and leptin (Maness et al., 1998) also reported rapid depletion of isotope from ventricular spaces with a concurrent accumulation in periventricular areas, especially those within the hypothalamus. Two anatomical considerations may allow for the observed diffusion away from the third ventricle to adjacent tissues. First, Ghersi-Egea at al. (1996) noted an accumulation of isotope in the optic and mammillary recesses or "outpockets" of the third ventricle despite a relatively speedy depletion of isotope from the ventricle itself. It may be that these cisterns serve as collecting pools from which drug may diffuse into surrounding tissue. Second, several hypothalamic nuclei, including the PVN, contain neurons whose dendritic processes and axonal fibers extend into the third ventricle and directly contact the CSF (Vigh et al., 2004). These observations may, in concert, promote local transport of CSF-borne molecules to periventricular hypothalamic regions. 
In the present studies, a high dose $(150 \mu \mathrm{g} / \mathrm{kg})$ peripheral injection of RU28362 serves as a positive control for GR immunostaining. With this injection regimen, we dependably see activated GR throughout the brain and pituitary. The extensive GR activation we observed following an i.p. injection of RU28362 is explained by the dynamics of cerebral blood flow. Once in the bloodstream, small molecules, if able to freely cross the blood-brain barrier, are distributed nearly instantaneously to all brain regions via an elaborate cerebral angioarchitecture. Capillaries are separated by approximately $40 \mu \mathrm{m}$; small molecules diffuse this distance in about $1 \mathrm{~s}$ (Pardridge, 1997). Therefore, one can expect very uniform and rapid delivery of a small lipid soluble molecule to all neural regions following peripheral injection. This efficiency, though, can be a double-edged sword when trying to deliver a steroid i.c.v. The closely spaced capillaries therefore make it quite likely that a lipid soluble small molecule will not diffuse very far before encountering a microcapillary and be carried downstream away from the intended site of action. Once in the bloodstream, the liver rapidly degrades steroids such as RU28362. A peptide or polar molecule would not have the ability to diffuse into these capillaries, and therefore would remain in the vicinity of the injection site much longer than a lipid soluble molecule. Further supporting this notion are two recent studies in which steroid diffusion was assessed with IHC following implantation of CORT pellets in specific brain nuclei (Akana et al., 2001; Scheuer et al., 2004). In both cases, very limited diffusion away from the implanted pellet was observed.

Reentry from the bloodstream into surrounding tissue may also be hampered by local expression in the ventricular walls of the P-glycoprotein, or multiple drug resistance (MDR), pump. The MDR pump is coded for by mdr1a and $m d r 1 b$ gene isoforms in rodents and is expressed on the luminal surface of brain epithelia and in brain capillaries (Regina et al., 1998; Kwan et al., 2002). Evidence implicating the MDR pump in regulating brain steroid diffusion is found in knockout studies in which $m d r 1 a / m d r 1 b-/$ - mice show a 10 -fold increase in [3H]-dexamethasone binding by brain GRs relative to controls following peripheral injection (de Kloet, 1997). It also may be that the MDR pump preferentially excludes RU28362, but not CORT. This could explain the observed small difference between the two drugs to diffuse into the PVN (Fig. 6). This would not be unprecedented as it has been shown in mouse and human that the MDR pump limits cortisol but not CORT access to brain (Karssen et al., 2001). Nevertheless, CORT delivered i.c.v. did not induce any greater GR occupancy outside the PVN than did RU28362.

So how do studies achieve positive results with i.c.v. drug administration? Further, how many research projects have been abandoned because of a negative result? The genesis of the experiments presented here lies in exactly such a finding. When a drug effect is obtained following i.c.v. drug delivery, a periventricular or peripheral site of action must be considered. If the drug can breach the blood-brain barrier, one must consider the possibility that delivery is effectively i.v. An important control for this pros- pect is an i.v. injection of the equivalent effective i.c.v. dose. In the absence of a drug effect, any conclusion is practically untenable.

\section{Implications for HPA negative feedback regulation}

Beyond the general implications for the merits and shortcomings of i.c.v. drug delivery, our data raise some intriguing questions about corticosteroid negative feedback. The most difficult to reconcile with previous negative feedback literature is the lack of functional suppression of stressinduced HPA activation despite partial GR occupancy in both PVN and pituitary (de Kloet et al., 1974; Dallman et al., 1987, 1992; de Kloet et al., 1998). One possible conclusion from these data is that hippocampal GR activation is necessary for HPA suppression; however, a peripheral injection of the GR agonist dexamethasone, which is precluded from occupying brain GR by the MDR pump, is alone sufficient to suppress stress-induced HPA activity (de Kloet et al., 1974; de Kloet, 1997). It is also worth noting that CORT, but not dexamethasone, implants in the dorsal hippocampus are sufficient to suppress ACTH production in ADX animals, so the possibility exists that the various GR agonists may differentially affect HPA output at diverse brain loci (Kovacs and Makara, 1988). Further complicating interpretation is the observed activation of pituitary GR in this study without a functional consequence (Fig. 8).

Collectively, the data point to a previously undescribed phenomenon. Partial occupancy of PVN and pituitary GR is not sufficient to suppress stress-induced HPA axis activity. From our observations, there appears to be some as-yet-unidentified threshold for GR occupancy within the pituitary that, when achieved, potently suppresses ACTH release. Defining the limits of this threshold and determining a mechanism that would allow such a binary response might provide significant illumination of HPA feedback physiology.

The data presented here demonstrate the need for careful examination of any result, positive or negative, obtained from studies employing i.c.v. as a methodology. Beyond the technical aspect, these data have important implications for HPA axis feedback physiology and the critical sites for glucocorticoid negative feedback.

\section{REFERENCES}

Aird RB (1984) A study of intrathecal, cerebrospinal fluid-to-brain exchange. Exp Neurol 86:342-358.

Akana SF, Chu A, Soriano L, Dallman MF (2001) Corticosterone exerts site-specific and state-dependent effects in prefrontal cortex and amygdala on regulation of adrenocorticotropic hormone, insulin and fat depots. J Neuroendocrinol 13:625-637.

Billiau A, Heremans $H$, Ververken D, van Damme J, Carton $H$, de Somer $P$ (1981) Tissue distribution of human interferons after exogenous administration in rabbits, monkeys, and mice. Arch Virol 68:19-25.

Cidlowski JA, Bellingham DL, Powell-Oliver FE, Lubahn DB, Sar M (1990) Novel antipeptide antibodies to the human glucocorticoid receptor: recognition of multiple receptor forms in vitro and distinct localization of cytoplasmic and nuclear receptors. Mol Endocrinol 4:1427-1437. 
Crawley JN, Fiske SM, Durieux C, Derrien M, Roques BP (1991) Centrally administered cholecystokinin suppresses feeding through a peripheral-type receptor mechanism. J Pharmacol Exp Ther 257:1076-1080.

Dallman M, Akana S, Cascio C, Darlington D, Jacobson L, Levin N (1987) Regulation of ACTH secretion: variations on a theme of $B$. Recent Prog Horm Res 43:113-173.

Dallman MF, Akana SF, Scribner KA, Bradbury MJ, Walker C-D, Strack AM, Cascio CS (1992) Stress, feedback and facilitation in the hypothalamo-pituitary-adrenal axis. J Neuroendocrinol 4:517-526.

Davson H (1996) Physiology of the CSF and blood-brain barriers. New York: CRC Press, Boca Raton.

de Kloet ER (1997) Why dexamethasone poorly penetrates in brain. Stress 2:13-20.

de Kloet ER, Vreugdenhil E, Oitzl M, Joels M (1998) Brain corticosteroid receptor balance in health and disease. Endocr Rev 19: 269-301.

de Kloet R, van der Vies J, de Wied D (1974) The site of the suppressive action of dexamethasone on pituitary-adrenal activity. Endocrinology 94:61-73.

de Lange EC, Danhof M, de Boer AG, Breimer DD (1994) Critical factors of intracerebral microdialysis as a technique to determine the pharmacokinetics of drugs in rat brain. Brain Res 666:1-8.

Fenstermacher J, Kaye T (1988) Drug "diffusion" within the brain. Ann N Y Acad Sci 531:29-39.

Fenstermacher JD, Davson H (1982) Distribution of two model amino acids from cerebrospinal fluid to brain and blood. Am J Physiol 242:F171-F180

Ghersi-Egea JF, Finnegan W, Chen JL, Fenstermacher JD (1996) Rapid distribution of intraventricularly administered sucrose into cerebrospinal fluid cisterns via subarachnoid velae in rat. Neuroscience 75:1271-1288.

Ginsberg AB, Campeau S, Day HE, Spencer RL (2003) Acute glucocorticoid pretreatment suppresses stress-induced hypothalamicpituitary-adrenal axis hormone secretion and expression of corticotropin-releasing hormone hnRNA but does not affect c-fos mRNA or fos protein expression in the paraventricular nucleus of the hypothalamus. J Neuroendocrinol 15:1075-1083.

Hazel JR, Sidell BD (1987) A method for the determination of diffusion coefficients for small molecules in aqueous solution. Anal Biochem 166:335-341.

Herman J, Cullinan W (1997) Neurocircuitry of stress: central control of the hypothalamo-pituitary-adrenocortical axis. Trends Neurosci 20: $78-84$.

Herman J, Cullinan W, Young E, Akil H, Watson S (1992) Selective forebrain fiber tract lesions implicate ventral hippocampal structures in tonic regulation of paraventricular nucleus corticotropinreleasing hormone $(\mathrm{CRH})$ and arginine vasopressin (AVP) mRNA expression. Brain Res 592:228-238.

Herman J, Schafer M-H, Young E, Thompson R, Douglass J, Akil H, Watson S (1989) Evidence for hippocampal regulation of neuroendocrine neurons of the hypothalamo-pituitary-adrenocortical axis. J Neuroscience 9:3072-3082.

Jacobson L, Brooke S, Sapolsky R (1993) Corticosterone is a preferable ligand for measuring rat brain corticosteroid receptors: competition by RU 28362 and RU 26752 for dexamethasone binding in rat hippocampal cytosol. Brain Res 625:84-92.

Karssen AM, Meijer OC, van der Sandt IC, Lucassen PJ, de Lange EC, de Boer AG, de Kloet ER (2001) Multidrug resistance Pglycoprotein hampers the access of cortisol but not of corticosterone to mouse and human brain. Endocrinology 142:2686-2694.

Kovacs K, Makara G (1988) Corticosterone and dexamethasone act at different brain sites to inhibit adrenalectomy-induced adrenocorticotropin hypersecretion. Brain Res 474:205-210.
Kwan P, Sills GJ, Butler E, Gant TW, Meldrum BS, Brodie MJ (2002) Regional expression of multidrug resistance genes in genetically epilepsy-prone rat brain after a single audiogenic seizure. Epilepsia 43:1318-1323.

Laugero KD, Gomez F, Manalo S, Dallman MF (2002) Corticosterone infused intracerebroventricularly inhibits energy storage and stimulates the hypothalamo-pituitary axis in adrenalectomized rats drinking sucrose. Endocrinology 143:4552-4562.

Madan AP, DeFranco DB (1993) Bidirectional transport of glucocorticoid receptors across the nuclear envelope. Proc Natl Acad Sci U S A 90:3588-3592.

Maness LM, Kastin AJ, Farrell CL, Banks WA (1998) Fate of leptin after intracerebroventricular injection into the mouse brain. Endocrinology 139:4556-4562.

McEwen BS (1982) Glucocorticoids and hippocampus: Receptors in search of a function. In: Current topics in neuroendocrinology: adrenal action on brain (Ganten D, Pfaff D, eds), pp 1-22. New York: Springer-Verlag.

Mink JW, Blumenschine RJ, Adams DB (1981) Ratio of central nervous system to body metabolism in vertebrates: its constancy and functional basis. Am J Physiol 241:R203-R212.

Munck A, Holbrook NJ (1984) Glucocorticoid-receptor complexes in rat thymus cells. Rapid kinetic behavior and a cyclic model. J Biol Chem 259:820-831.

Nagaraja TN, Patel P, Gorski M, Gorevic PD, Patlak CS, Fenstermacher JD (2005) In normal rat, intraventricularly administered insulin-like growth factor-1 is rapidly cleared from CSF with limited distribution into brain. Cerebrospinal Fluid Res 2:5.

Pardridge WM (1997) Drug delivery to the brain. J Cereb Blood Flow Metab 17:713-731.

Pitha J (1989) Cyclodextrins: solutions to insolubility. In: Neurotransmissions, Vol. 5, pp 1-4. Natick, MA: Research Biochemicals Incorporated.

Pitha J, Harman SM, Michel ME (1986) Hydrophilic cyclodextrin derivatives enable effective oral administration of steroidal hormones. J Pharm Sci 75:165-167.

Raaka BM, Samuels HH (1983) The glucocorticoid receptor in GH1 cells. Evidence from dense amino acid labeling and whole cell studies for an equilibrium model explaining the influence of hormone on the intracellular distribution of receptor. J Biol Chem 258:417-425.

Regina A, Koman A, Piciotti M, El Hafny B, Center MS, Bergmann R, Couraud PO, Roux F (1998) Mrp1 multidrug resistance-associated protein and P-glycoprotein expression in rat brain microvessel endothelial cells. J Neurochem 71:705-715.

Reul J, de Kloet E (1985) Two receptor systems for corticosterone in rat brain: microdistribution and differential occupation. Endocrinology 117:2505-2511.

Sackey FN, Hache RJ, Reich T, Kwast-Welfeld J, Lefebvre YA (1996) Determinants of subcellular distribution of the glucocorticoid receptor. Mol Endocrinol 10:1191-1205.

Scheuer DA, Bechtold AG, Shank SS, Akana SF (2004) Glucocorticoids act in the dorsal hindbrain to increase arterial pressure. Am J Physiol Heart Circ Physiol 286:H458-H467.

Turnbull AV, Rivier CL (1998) Intracerebroventricular passive immunization. II. Intracerebroventricular infusion of neuropeptide antisera can inhibit neuropeptide signaling in peripheral tissues. Endocrinology 139:128-136.

Vigh B, Manzano e Silva MJ, Frank CL, Vincze C, Czirok SJ, Szabo A, Lukats A, Szel A (2004) The system of cerebrospinal fluid-contacting neurons. Its supposed role in the nonsynaptic signal transmission of the brain. Histol Histopathol 19:607-628. 